\title{
THE CHARACTERISTIC BEHAVIOURAL TRAITS OF GENERATION-Z A STUDY IN RURAL DEMOGRAPHY SET UP OF INDIA, SONBHADRA, U.P.
}

\author{
Deepshikha Verma, \\ Senior Manager (Business Excellence), Rihand Nagar, NTPC Ltd. India \\ Ritesh Bhardwaj, \\ Senior Manager (Human Resource), Rihand Nagar, NTPC Ltd. India \\ Roobi Sachan \\ Deputy Manager (Planning \& Systems), Rihand Nagar, NTPC Ltd. India
}

\begin{abstract}
Understanding the behavioural traits of young cohort in Indian scenario is an important area to delve in. It is accepted fact that Gen-Z is digitally smart, selfmotivated, more realistic and critical thinkers. Acceptance of new thoughts and understanding of new behavioural patterns is often difficult for the elders associated with them. The current study deals with the results of the research conducted through a questionnaire specially designed for the purpose. It highlights the salient points emerged out of study conducted on students from class IX to XII of strategically selected six schools in Sonbhadra District of Uttar Pradesh. Statistical calculations have also been made to find out the correlation coefficient between different traits to establish a relationship between distinct behaviour traits exhibited by the digital generation. Efforts have been put to find similarities or differences in the behavioural traits of Gen$Z$ based at rural or urban areas but exposed to at least basic modern age technologies. The results might be useful in future course of actions wherein the information may be taken as one of the input.
\end{abstract}

Keyword: Behavioural traits, Gen-Z, Rural, technology

Cite this Article:. Deepshikha Verma, Ritesh Bhardwaj and Roobi Sachan, The Characteristic Behavioural Traits of Generation-Z a Study an Rural Demography Set Up of India, Sonbhadra, U.P, Journal of Management, 6(1), 2019, pp.55-61. http://www.iaeme.com/jom/issues.asp?JType=JOM\&VType=6\&IType=1 


\section{INTRODUCTION}

A lot has been said and studied around the globe regarding the characteristic traits of Generation $-\mathrm{Z}$ or commonly referred to as Gen-Z. People across different fields - whether they are marketers, leaders, parents, employers, environmentalists, all are worried to capture the insights of the attitudes, behaviours, beliefs and thinking styles of this young cohort because whatever may be the field, Gen- $Z$ is poised to rule. This digital disruptor generation shall very soon start driving the trends. This generation shall emerge as young adults, influence the consumer market, change the way organisations work and make the world very clear that the time has arrived for traditional approach in all the processes to take a back seat.

Technology is what has kept this generation entirely different from the earlier generations including their millennial counterparts. While Millennial were raised with technology and they witnessed the emergence of smart phones and Wi-Fi connectivity, Gen- $Z$ was born into it. Gen$\mathrm{Z}$ do not know about the world that existed before without the use of internet and smart phones. And as a result, this generation is totally integrated into digital lifestyles ${ }^{[1]}$.

By 2020, India's population is expected to become the world's youngest ${ }^{[2]}$. India, which has about 1.3 billion people, will see its Gen-Z population rise to 472 million by $2019^{[3]}$. Unlike many other countries, India enjoys the privilege that a large percentage of its population is young.

Gen-Z in India do not form a homogeneous group. The rural/urban divide is an important factor that determines the attitude and behavioural pattern of this young generation. For example, the degree of affinity and association with family is one such cause that affects personality traits of Indian youth. The Indian children are raised in a more protective environment and so in majority cases, their decisions are influenced by their parents and family. With the variability in the degree of affinity and association the actualization of innate desires may vary amongst young generation. So, it is very much possible that the same generation cohort may behave and think differently if raised in a different environment.

A lot of surveys have been carried out to establish the behavioural trend of this new generation cohort worldwide. But where we can see that in advanced and industrialised countries, there is a sharp difference in opinion and belief system across generations, in India there is a strong continuity of belief.

The total urban population of India, as in 2017 is just $33.6 \%$ of total population ${ }^{[4]}$. "India lives in villages" were the golden words of Mahatma Gandhi decades ago. Majority of Indian population still resides in the villages where they have a limited access to opportunities in comparison to their urban counterparts who are much more equipped with modernity.

\section{GEOGRAPHICAL LOCATION \& DESCRIPTION OF STUDY AREA}

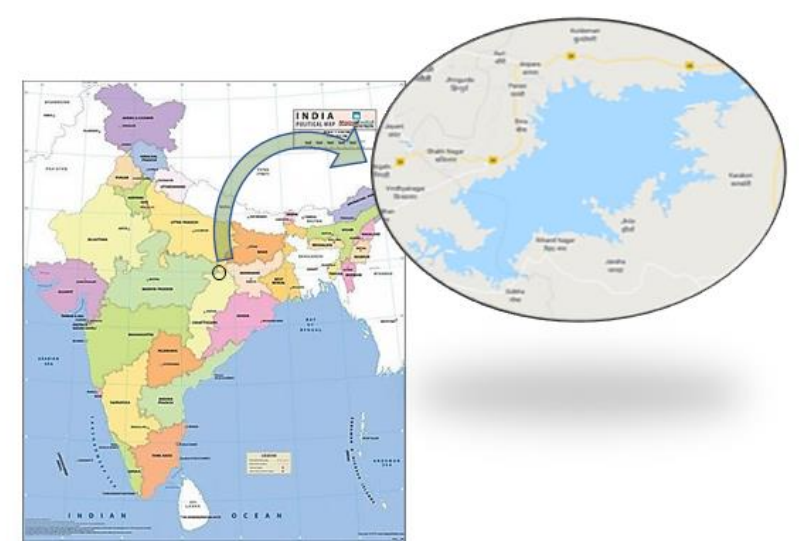

Figure 1 Location of area under study (Source: Google Maps) 
Sonbhadra district is the second largest district in Indian state of Uttar Pradesh. The district borders four states namely Madhya Pradesh, Chattisgarh, Jharkhand and Bihar. Referred to as 'Energy capital of India', this area is a major hub of power plants around Govind Ballabh Pant Sagar with three biggest power plants of NTPC Ltd. Rihand Super Thermal Power Station, Vindhyachal Super Thermal Power station and Singrauli Super Thermal Power station in close vicinity.

The scope of current study includes the children studying in class IX to XII in Six different schools namely St. Joseph School, DAV and Kendriya Vidyalaya in NTPC- Rihand Nagar township and St. Joseph School, Kendriya Vidyalaya and Vivekanand Sr. Sec School in NTPCShakti Nagar township.

The schools and classes mix have been selected specifically and strategically to cover a larger population of students from a group of families with distinct standard of living, intellect of parents, exposures, facilities, comfort etc.

The students studying in these schools form a mix group of children of NTPC officials and the children belonging to associates, agencies, workers and inhabitants of nearby villages. With all such discrete backgrounds the group is still found homogeneous in terms of availability of facilities like faculty, class room infrastructure, library, laboratories, sports and recreation activities. Further, the overall access to resources is still limited for all the children as district Sonbhadra falls in bottom 20 composite ranking in India as per NITI Aayog's "Aspiration District Baseline Ranking 2018”. ${ }^{[6]}$

\section{RESEARCH OBJECTIVE}

The purpose of this study is to understand the behavioural traits through analysis of perceptions of selected group of Gen-Z individuals belonging to a backward district of India but exposed to basic technologies and infrastructural facilities of modern world.

The study also aims to bring out the similarities or differences in behaviour, approach, belief system and attitudes of children who live in backward demography of India and having access to limited facilities in comparison to their counterparts living in metro or smart cities and believed to have a much broader outlook with access to latest technology.

\section{RESEARCH METHODOLOGY}

To understand the characteristic behaviour of the group chosen for study in a broader way, it was pertinent to formulate a methodology that would extract the maximum information about the attitudes and thinking patterns of Gen-Z being brought up in a world of limited resources. Accordingly, the following methodology was devised -

- Literature survey to get information about characteristic traits of Gen-Z around the globe.

- To conduct dip stick survey amongst the targeted group of students in the selected schools of District Sonbhadra to feel the pulse of students who are ready to face the competitive scenario.

- Research on primary data.

- Use of statistical tools to evaluate the correlation between the habits and traits found in Gen-Z in urban metro cities with that of rural location.

\section{DETAILS OF RESEARCH}

- The results and inference drawn in current work is based on primary data collected by surveying a group of 927 students in Sonbhadra District by means of a questionnaire. 
- Secondary data is based on gathering relevant information from journals, direct discussion with the school faculty of surveyed children, and online articles.

\subsection{Research Limitation-}

The precision of the estimates are limited due to limited sample size and limited area chosen for study.

\subsection{Survey Results}

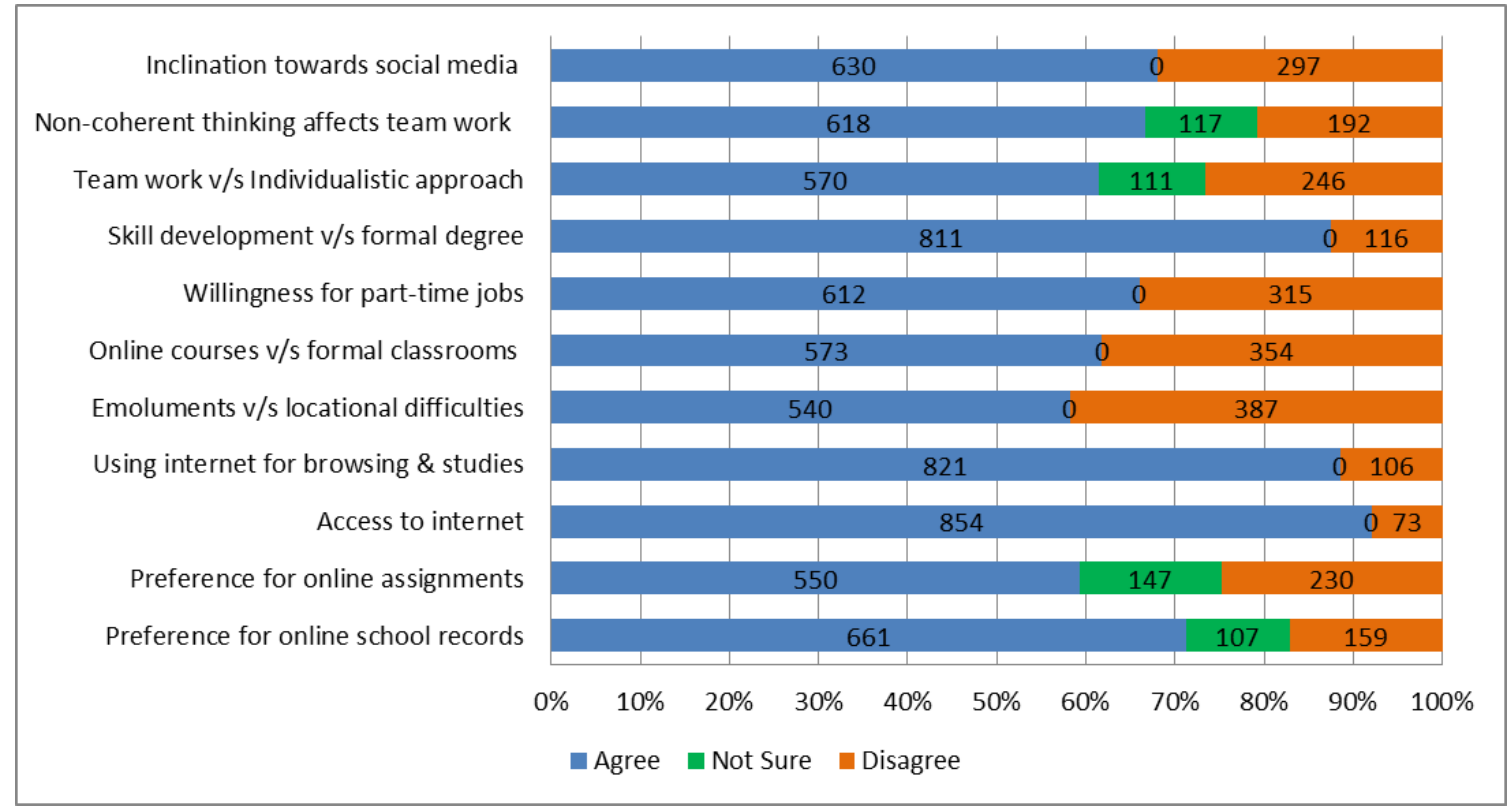

Figure 2 Results of Primary survey (Sample size $=927$ no.)

i. The online mechanism of various processes like attendance, marks communication etc. is preferred by the respondents (71\% responded positively) which shows their awareness and inclination towards ease out way of information gathering and communicating apart from data retrieval.

One of the important reason for their choice may be their concern towards environment i.e. reduction in use of paper.

ii. $92.1 \%$ of respondents have access to internet either at home or school and they use it for studies or for browsing social networking websites. This is in sync with the results of TCS survey conducted on Gen-Z to capture digital habits of children belonging to urban cities of India. According to TCS survey, the most popular mode of accessing the internet is Desktops/ home PCs/ laptops closely followed by smart phones ${ }^{[7]}$.

iii. Although having limited access to such opportunities, yet $59.3 \%$ of the respondents prefer online assignments to routine homework. Further, a similar percentage of respondents prefer online courses over formal classroom lectures. This may be because instant grading and feedbacks are innate requirements of Gen-Z.

Here one of the probable reasons for not preferring the online methods of assignments and feedback by a significant number of respondents may be because such facilities are not in vogue at townships at present. However, it is still evident that majority of Gen-Z students prefer non-traditional teaching methods and like using logic-based approaches and experiential learning ${ }^{[8]}$. 
The Characteristic Behavioural Traits Of Generation-Z A Study In Rural Demography Set Up Of India, Sonbhadra, U.P.,

iv. Apart from their inclination towards technology the young cohort are found more attracted towards social networking online instead of in-person meetings. The young generation was found to be more willing to pursue their hobbies or chose to connect with their role models through social networking sites. Besides, only $32.03 \%$ of respondents opted to meet families \& friends in-person often whereas others are satisfied connecting on air.

v. The charisma in personality and preventability is a desire of everybody and the targeted young cohort is not an exception. When asked which interpersonal skill they would like to improve upon, $59.5 \%$ of them wish to improve their communication skills while $40.5 \%$ of respondents wish to work more upon public speaking.

vi. No wonder about the results of Gen-Z about their dependability on Google (or search engines) for clarifying their doubts. However, due to the environmental effects still they fall back on their teachers for this purpose. Further, no surprise to hear from them that they least prefer to clarify their academic doubts through parents.

vii. The Gen-Z wants instant gratification and feed-backs; however they want all this on their wish. They wanted to seek feedback only when they need it ${ }^{[9]}$. They don't like continuous monitoring or regular instructions.

viii. The new generation is Entrepreneur's era, $87.48 \%$ respondents believe that skill development is more useful than formal degrees and $66 \%$ prefer to carry on a part time job while pursuing their college. This also reflects they want financial security. As the young minds are buzzing with creative and innovative ideas, India has emerged as a third largest start up base only behind US and UK. ${ }^{[10]}$

\subsection{Statistical approach to study relationship between distinct behavioural traits of Gen-Z}

For the responses against the below mentioned distinct behavioural traits, the coefficient of correlation has been found using statistical tool.

Table 1 Abbreviations of Traits used for Correlation Study

\begin{tabular}{|c|c|c|c|}
\hline Particular & Code & Particular & Code \\
\hline Preference for online school records & A1 & Willingness for part-time jobs & A7 \\
\hline Preference for online assignments & A2 & Skill development v/s formal degree & A8 \\
\hline Access to internet & A3 & Team work v/s Individualistic approach & A9 \\
\hline Using internet for browsing \& studies & A4 & Non-coherent thinking affects team work & A10 \\
\hline Emoluments v/s locational difficulties & A5 & Inclination towards social media & A11 \\
\hline Online courses v/s formal classrooms & A6 & & \\
\hline
\end{tabular}

By implementing the statistical tool the following matrix have been formulated for the coefficients of correlation amongst the above mentioned particulars: 
Deepshikha Verma, Ritesh Bhardwaj and Roobi Sachan

\begin{tabular}{|c|c|c|c|c|c|c|c|c|c|c|c|}
\hline & A1 & A2 & A3 & A4 & A5 & A6 & A7 & A8 & A9 & A10 & A11 \\
\hline A1 & 1 & 0.87 & 0.61 & 0.67 & 0.42 & 0.65 & 0.61 & 0.48 & 0.45 & 0.26 & 0.54 \\
\hline A2 & 0.87 & 1 & 0.54 & 0.68 & 0.49 & 0.59 & 0.42 & 0.58 & 0.52 & 0.49 & 0.71 \\
\hline A3 & 0.61 & 0.54 & 1 & 0.92 & 0.09 & 0.61 & 0.28 & 0.62 & 0.29 & 0.52 & 0.84 \\
\hline A4 & 0.67 & 0.68 & 0.92 & 1 & 0.47 & 0.76 & 0.56 & 0.82 & 0.55 & 0.31 & 0.95 \\
\hline A5 & 0.42 & 0.49 & 0.09 & 0.47 & 1 & 0.59 & 0.83 & 0.54 & 0.84 & 0.66 & 0.48 \\
\hline A6 & 0.65 & 0.59 & 0.61 & 0.76 & 0.59 & 1 & 0.38 & 0.46 & 0.83 & 0.89 & 0.85 \\
\hline A7 & 0.61 & 0.42 & 0.28 & 0.56 & 0.83 & 0.38 & 1 & 0.61 & 0.61 & 0.22 & 0.39 \\
\hline A8 & 0.48 & 0.58 & 0.62 & 0.82 & 0.54 & 0.46 & 0.61 & 1 & 0.30 & 0.36 & 0.78 \\
\hline A9 & 0.45 & 0.52 & 0.29 & 0.55 & 0.84 & 0.83 & 0.61 & 0 & 1 & 0.82 & 0.60 \\
\hline A10 & 0.26 & 0.49 & 0.52 & 0.31 & 0.66 & 0.89 & 0.22 & 0.36 & 0.82 & 1 & 0.81 \\
\hline A11 & 0.54 & 0.71 & 0.84 & 0.95 & 0.48 & 0.85 & 0.39 & 0.78 & 0.60 & 0.81 & 1 \\
\hline
\end{tabular}

Figure 3 Co-efficient of co-relation values between different sets of trait

\subsection{The below mentioned inferences may be drawn with the above matrix:}

There is a strong correlation amongst behavioural traits of preferring online facilities if there is access to internet. Despite being at a remote location with limited facilities, the desire towards having an edge over technology is evident.

Strong positive correlation is also found between traits A7 \& A8 which shows the entrepreneurial capabilities amongst the young cohorts. They are having clear mind set at this early age about competitiveness in market and lack of opportunities, thus they want to keep themselves saleable with their specialized skills. The positive correlation between A5 and A7 deduce the materialistic desires amongst them, however they are ready to pay for it, whether in terms of hard work or sacrifice on the front of family affinity. They expect to obtain value from the educational experience and be prepared to move into a career that offers job security ${ }^{[11]}$.

Strong correlation has been found between A9 and A10 which shows the individualistic approach of young cohorts over the team work. This could again be attributed to the prevailing nuclear family set-ups with both working parents and more and more dependability on mobile phones \& tablets. This can be further confirmed with a strong positive co-relation coefficient of A 10 and A 11. The respondents prefer to get connected with others over social sites instead of spending time with them in person. They also avoid regular monitoring and continuous interference in their work.

\section{CONCLUSION}

The young cohort shares similar behavioural patterns of technological disruptions irrespective of urban/ rural divide if at least basic infrastructural facilities are made available to them. In such a scenario it is very important to develop a culture of creativity \& entrepreneurship in India as providing job to Indian youth is the biggest challenge the country is facing at present. But through our study, we can say that Gen- $Z$ in India is much smarter, more digitally advance and more confident in making a niche for themselves. Also, they have an entrepreneur approach and are better leaders. So, what is required is to give them a platform and support so that we can raise entrepreneurs and create jobs. Some of the initiatives by Government of India are being taken time to time for promoting innovation \& creativity to capture the ideas of young minds and ensuring their implementation to boost up the economy.

The Government of India has also formulated a National Youth Policy covering eleven priority areas- Education, Employment and Skill Development, Entrepreneurship, Health and Healthy Lifestyle, Sports, Promotion of Social values, Community Engagement, Participation in Politics and Governance, Youth Engagement, Inclusion, and social Justice- which provides the young generation a strong road map for a successful future. 
This sort of approach from Government will be able to provide basic infrastructural facilities in every nook and corner of country and in turn make the environment conducive for development of young cohort in the way they wish to grow.

The continuity in behavioural traits throughout the cross section will give an ease in formulation and implementation of various schemes and programs as the focus is not going to divert with varying needs of various segments.

What need to be done is just to include these behavioural traits as an important input while designing Job Schemes, Academic Infrastructure and Calculation of Job worth etc. This will ensure that the interest of individual is intact and output is maximized.

\section{REFERENCE}

[1] A.P Singh, Jianguanglung Dangmei: Understanding the Gen-Z, the future workforce, South -Asian Journal of Multidisciplinary Studies (SAJMS) ISSN:2349-7858:SJIF:2.246:Volume 3 Issue 3 Retrieved from Financial Express, March 26,2017

[2] Lee J Miller, Wei Lu: Gen Z Is Set to Outnumber Millennials Within a Year, Retrieved from www.bloomberg.com

[3] Urbanization in India 2017: Retrieved from http://www.statista.com

[4] https://www.google.co.in/maps/@24.1203203,82.8723838,10.75z?hl=en

[5] Transformation of Aspirational Districts - Aspirational Districts Baseline Ranking March rieved from http://niti.gov.in/content/aspirational-districts-baseline-ranking-map

[6] Press Release:10 Things to know about India's Gen-Z, June12 2016 Retrieved from http://www.tcs.com

[7] Seemiller C, Grace M. Gen-Z Goes to College, San Francisco, California:Jossey Bass, 2016

[8] Anjali Singh: Challenges and Issues of Gen-Z, IOSR Journal of Business and Management (IOSR-JBM) e-ISSN: 2278-487X, p-ISSN: 2319-7668. Volume 16, Issue 7.Ver. I (July. 2014), PP 59-63

[9] DeboJyoti Ghosh: India named world's third-largest start up base behind US and UK, Retrieved from www.forbesindia.com.

[10] Debbie C. Hampton ,Yolanda Keys: Gen-Z students: Will they change our nursing classrooms?, Journal of Nursing Education and Practice 2017, Vol7, No.4 